\title{
CD34 Is Required for Infiltration of Eosinophils into the Colon and Pathology Associated with DSS-Induced Ulcerative Colitis
}

Steven Maltby, Carolin Wohlfarth, Matthew Gold, Lori Zbytnuik, Michael R. Hughes,

and Kelly M. McNagny

From The Biomedical Research Centre, The University of British Columbia, Vancouver, British Columbia, Canada

Eosinophil migration into the gut and the release of granular mediators plays a critical role in the pathogenesis of inflammatory bowel diseases, including ulcerative colitis. We recently demonstrated that eosinophil migration into the lung requires cell surface expression of the sialomucin $\mathrm{CD} 34$ on mast cells and eosinophils in an asthma model. Based on these findings, we investigated a similar role for $\mathrm{CD} 34$ in the migration of eosinophils and other inflammatory cells into the colon as well as explored the effects of CD34 ablation on disease development in a dextran sulfate sodium-induced model of ulcerative colitis. Our findings demonstrate decreased disease severity in dextran sulfate sodiumtreated $\mathrm{Cd} 34^{-/-}$mice, as assessed by weight loss, diarrhea, bleeding, colon shortening and tissue pathology, compared with wild-type controls. CD34 was predominantly expressed on eosinophils within inflamed colon tissues, and $\mathrm{Cd}_{34^{-/-}}$animals exhibited drastically reduced colon eosinophil infiltration. Using chimeric animals, we demonstrated that decreased disease pathology resulted from loss of CD34 from bone marrow-derived cells and that eosinophilia in Cd $34^{-1-} \mathrm{IL}^{\mathrm{Tg}}$ animals was sufficient to overcome protection from disease. In addition, we demonstrated a decrease in peripheral blood eosinophil numbers following dextran sulfate sodium treatment. These findings demonstrate that CD34 was expressed on colon-infiltrating eosinophils and played a role in eosinophil migration. Further, our findings suggest $\mathrm{CD} 34$ is required for efficient eosinophil migration, but not proliferation or expansion, in the development of ulcerative colitis. (Am J Pathol 2010, 177:1244-1254; DOI: 10.2353/ajpath.2010.100191)
The two major forms of inflammatory bowel disease, Crohn's disease, and ulcerative colitis, are multifactorial intestinal disorders, which have become increasingly prevalent in Western society. Clinical symptoms of these disorders include weight loss, diarrhea, bleeding, fever, and shortening of the colon. ${ }^{1}$ Typical histological findings from colon tissue from ulcerative colitis patients reveal the infiltration of leukocytes into the gut mucosa, goblet cell depletion, crypt abscesses, and distortion of mucosal glands. ${ }^{1}$ Despite the increasing prevalence of these disorders, our understanding of how they originate and develop is still quite poor.

The immune cells resident in the intestines are continuously exposed to both endogenous and exogenous antigens and play a key role in regulating food tolerance and defense against gut pathogens. Dysregulation of this immune response results in mucosal inflammation and tissue damage, leading to the onset of disease. ${ }^{2}$ One key cell type in the diseased colon is the eosinophil, and several lines of evidence suggest a role for eosinophils in the pathology of ulcerative colitis, in both human patients and animal models. In patients with ulcerative colitis and Crohn's disease, the numbers of eosinophils are significantly elevated in the colon, compared with healthy controls. $^{3-5}$ Eosinophils also respond to a number of cytokines associated with inflammatory bowel disease, including eotaxin, which is increased in the serum of patients with inflammatory bowel disease,${ }^{6}$ and interleu-

Supported by operating grants from the CIHR (\#MIF-79631 and \#MOP84545) and the AllerGen Network Centre of Excellence (Grant 3.14). S.M. and M.R.H. hold Canadian Institutes of Health Research (CIHR) and Heart and Stroke Foundation of Canada Transfusion Science Fellowships from the Centre for Blood Research (CBR) at the University of British Columbia and M.G. holds funding from the CIHR and Michael Smith Foundation of Health Research Transplantation Training Program. K.M.M. is a Michael Smith Foundation for Health Research Scholar (Senior) and CBR Member. Accepted for publication May 20, 2010.

None of the authors disclosed any relevant financial relationships.

Address reprint requests to Dr. Kelly M. McNagny, Ph.D., The Biomedical Research Centre, University of British Columbia, 2222 Health Sciences Mall, Vancouver, British Columbia, V6T 1 Z3 Canada, E-mail: kelly@brc.ubc.ca. 
kin (IL)- 5 and tumor necrosis factor (TNF) $\alpha$, both of which are present in perfusion fluids isolated from patients with ulcerative colitis. ${ }^{7}$ Additionally, high levels of the eosinophil granule proteins eosinophil peroxidase/eosinophil protein $\mathrm{X}$, major basic protein (MBP), and eosinophil cationic protein are found in biopsy specimens from ulcerative colitis patients and correlate with disease severity. ${ }^{8,9}$ While the potential role of eosinophils in inflammatory bowel disease development is not clear, tissue eosinophilia is well documented in other mucosal inflammatory diseases, such as eosinophilic gastroenteritis and eosinophilic esophagitis. ${ }^{10,11}$

In mice, oral administration of dextran sulfate sodium (DSS) provokes intestinal inflammation with similar features to human ulcerative colitis and serves as a valuable model of colitis. While increasing interest in colitis disease pathology research has focused on the role of infiltrating immune cells, most studies highlight roles for neutrophils. However, several studies have indicated a critical role for eosinophils in colitis pathology. Eotaxins act as chemoattractants for eosinophil migration and studies using eotaxin-1-1- , eotaxin- $2^{-/-}$and eotaxin-1/ $2^{-1-}$ mice reveal an ameliorated form of colitis, after DSS treatment. ${ }^{12,13}$ Further, decreased disease severity is associated with decreased eosinophil infiltration into the colon in eotaxin- $1^{-1-}$ mice,$^{13}$ demonstrating the importance of eosinophil migration in disease pathology. The adhesion molecule ICAM-1 is expressed by circulating eosinophils and plays a key role in eosinophil migration into the large intestine in hapten-induced colitis. ${ }^{14}$ Furthermore, a key role for eosinophil degranulation, particularly release of eosinophil peroxidase and eosinophil cationic protein, has been shown in DSS-induced ulcerative colitis. Eosinophil peroxidase ${ }^{-1-}$ mice, or mice treated with the eosinophil peroxidase-inhibitor resorcinol, developed attenuated DSS-induced colitis ${ }^{13}$ and antibody blockade of eosinophil cationic protein, in a rat DSS model results in reduced disease pathology. ${ }^{15}$ Finally, total ablation of eosinophils in both the PHIL and the $\triangle \mathrm{db}$ IGATA-1 mouse models results in decreased disease severity and gut pathology in two independent studies. ${ }^{12,16}$

Despite findings of a critical role for eosinophils in colitis pathology, somewhat surprisingly, deletion of the II-5 gene has no effect on disease severity. ${ }^{17} \mathrm{IL}-5$ promotes eosinophil development and expansion and while IL-5 $5^{-1-}$ mice have normal peripheral eosinophil numbers, they are unable to develop eosinophilia. ${ }^{17}$ Several groups have demonstrated that IL-5-deficient mice exhibit normal DSS colitis induction, with observed eosinophil infiltration of the gut, and demonstrate that IL-5 is not required for the development of ulcerative colitis. ${ }^{13,18}$ Taken together, these findings suggest that while eosinophil migration and degranulation are critical for disease pathology, IL-5-mediated eosinophil expansion and survival is not required.

CD34 is a transmembrane sialomucin and although it has been widely used as a marker of hematopoietic stem cells for almost 30 years and more recently for other stem cell/progenitor types, such as muscle satellite cells, ${ }^{19}$ adipogenic precursors ${ }^{20}$ and epidermal precursors, ${ }^{21}$ its function remains unclear. In high endothelial venules (HEVs), where CD34 is uniquely glycosylated to bind L-selectin, CD34 promotes cell adhesion in the recruitment of naïve lymphocytes to secondary lymphoid organs. ${ }^{22,23}$ However, HEV cells appear to be the only cell type able to modify CD34 for L-selectin interaction, thus $\mathrm{L}$-selectin binding is not thought to be a general function for CD34 on other cell types. ${ }^{24}$

In addition to expression on progenitor cell types, CD34 is also expressed on differentiated leukocytes, including mast cells, ${ }^{25}$ dendritic cell precursors and eosinophils. ${ }^{26,27}$ Our studies with $C d 34^{-1-}$ mice demonstrate that CD34 plays a key role in anti-adhesion on these mature cell types. CD34-deficient mast cells exhibit dramatically enhanced homotypic cell aggregation in vitro and delayed tissue homing in vivo in a water ablation model, particularly when the related sialomucin, CD43, is also deleted. ${ }^{28}$ Likewise, mast cell and eosinophil accumulation in the lung in an OVA-induced asthma model is significantly decreased in $\mathrm{Cd} 34^{-1-}$ mice and $\mathrm{Cd} 34^{-1-}$ eosinophils exhibit impaired migration to eotaxin-1 in vitro. ${ }^{27}$ Further, we observed that the reduced accumulation of mast cells and eosinophils in Cd34 ${ }^{-1-}$ tissues in asthma results in reduced disease symptoms and that CD34 loss specifically on hematopoietic cells is sufficient to block disease. ${ }^{27}$ Finally, hematopoietic stem cells derived from CD34-deficient mice show significantly decreased bone marrow repopulation in competitive reconstitution assays, ${ }^{29}$ demonstrating that on hematopoietic precursor cells, CD34 is critical for optimal cell migration.

Based on these previous findings, we hypothesized that CD34 plays a similar role in facilitating eosinophil migration in other inflammatory disease models. As ulcerative colitis, in a DSS-induced mouse model, appears to be dependent on eosinophil migration, we tested whether CD34 deficiency leads to attenuated symptoms in DSS-induced experimental colitis. In this study, we show that $\mathrm{Cd} 34^{-1-}$ mice exhibit a significantly milder colitis than $\mathrm{Cd} 34^{+/+}$mice and that the primary inflammatory population expressing CD34 within the inflamed colon is eosinophils. Further, using hematopoietic chimeras, we demonstrate that CD34 expression on hematopoietic cells is critical for the attenuated disease phenotype. Interestingly, our studies show that peripheral eosinophil levels decrease with the onset of disease pathology and that eosinophilia alone, in the absence of DSS treatment (in IL5 ${ }^{\text {Tg }}$ animals), is sufficient to induce colon shortening. Finally, we demonstrate that eosinophilia in $\mathrm{Cd}_{3} 4^{-1-}$ mice is sufficient to overcome the reduced colon eosinophil infiltration and protection from disease. This study further supports the model that eosinophils, and particularly eosinophil migration, are required for the development of ulcerative colitis. It also furthers our understanding of CD34 expression and function in disease and suggests CD34 is a potential therapeutic target to inhibit eosinophil migration in disease. 


\section{Materials and Methods}

\section{Mice}

We used $\mathrm{Cd} 34^{-1-}$ (kindly provided by Dr. T. W. Mak ${ }^{30}$ ) and IL5 transgenic (IL5 $5^{\mathrm{Tg}}$; NJ. $1638 \mathrm{CD}^{\mathrm{IL}-5+}$ ) mice expressing IL-5 under the control of the CD3 promoter (kindly provided by Dr. J. Lee ${ }^{31}$ ) with C57BI/6 controls throughout our experiments. Sex and age-matched 6- to 10-week-old mice were maintained in specific pathogenfree conditions at The Biomedical Research Centre and all procedures were approved by the local animal care committee.

\section{Bone Marrow Reconstitutions}

To assess the role of CD34 on hematopoietic versus nonhematopoietic populations, chimeras were created using the Ly 5.1/5.2 reconstitution model. Briefly, bone marrow was isolated from either donor wild-type (Ly 5.2) and $\mathrm{Cd} 34^{-1-}$ (Ly 5.2) or Ly 5.1 mice and transplanted into recipient Ly 5.1 or wild-type and $\mathrm{Cd} 34^{-1-}$ mice respectively, as specified in the text. Marrow cells $\left(\sim 10^{6}\right)$ were injected intravenously into lethally irradiated (11 Gy) recipient animals and animals were rested for 10 to 12 weeks to allow for complete bone marrow reconstitution. Reconstitution levels were evaluated by staining for Ly 5.2 and Ly 5.1 expression in peripheral blood and mice were considered reconstituted when hematopoietic cells were $>80 \%$ donor-derived.

\section{Induction and Assessment of DSS Ulcerative Colitis}

Experimental ulcerative colitis was induced in mice as previously described. ${ }^{32}$ Briefly, drinking water was supplemented with $3.5 \%$ w/v DSS (36,000 to 50,000 kDa; MP Biomedicals LLC, Solon, $\mathrm{OH}$ ) for 7 days. On day 7 , mice were returned to regular drinking water.

To assess disease severity and progression, mice were monitored daily for body mass, diarrhea and rectal bleeding by visual inspection. Diarrhea and bleeding were each given a score of 0 or 1 based on the presence of symptoms and added together to give a daily diarrhea/ bleeding score (0 to 2). Body weight was measured daily and expressed as percentage body mass by normalization to the initial body mass at day 0 . In some experiments, mice were bled via the saphenous vein to assess peripheral blood eosinophil levels on days 0 and 7 .

On day 8, animals were sacrificed and tissues collected. The intestine was excised and colon length measured. Excised colon tissues were gently rinsed in sterile PBS and processed for flow cytometry, cytokine assessment, or histology, as outlined below.

\section{Colon-Infiltrating Cell Isolation}

Colon tissues were cut into pieces and incubated in digestion solution $(200 \mathrm{U} / \mathrm{ml}$ collagenase IV [Sigma-Aldrich, St. Louis, MO] in PBS) for 60 minutes at $37^{\circ} \mathrm{C}$.
Digested tissues were then forced through a 70- $\mu$ m nylon strainer, rinsed in PBS and collected. Cells were spun down, resuspended in $3 \mathrm{ml}$ of $30 \%$ Percoll solution, and centrifuged for 15 minutes at $1300 \mathrm{rpm}$ to remove undigested tissue and fat. The resulting cell pellet was again washed in sterile PBS and plated for flow cytometry staining.

\section{Flow Cytometry Staining of Peripheral Blood and Bone Marrow Eosinophils and Colon Infiltrating Immune Cells}

Peripheral blood was obtained by saphenous bleed into EDTA-coated tubes and bone marrow was prepared by flushing extracted femur bones. Red cells were removed using hypotonic lysis buffer, and unlysed cells were washed and used for further flow analysis. Cells were first blocked in 10\% mouse serum and stained for CD45 and CCR3 expression (using anti-CCR3-PE [R\&D Systems, Minneapolis, MN] and anti-CD45.2-FITC). Colon tissue isolated cells were stained using anti-CD34-biotin (BD Pharmingen, San Diego, CA) followed by streptavidinAPC (BD Pharmingen), in addition to antibodies against CD45 and CCR3. In reconstituted animals, antibodies recognizing CD45.1 and CD45.2 (conjugated to Alexa 488 and PerCP, respectively) were used to identify donor versus recipient-derived hematopoietic cells within the colon tissue.

To assess cell frequencies and CD34 expression, data were collected on a BD FACSCalibur (BD Biosciences, Mountain View, CA) and analyzed with FlowJo software (Treestar, Ashland, OR). Total white blood cell counts were determined manually using a hemacytometer. To confirm the identity of CD34-expressing cells, $\mathrm{CD}_{4} 5^{+} \mathrm{CCR}^{+}$cells were sorted from lamina propria cell isolates on a FACSVantage cell sorter (BD Biosciences, Mountain View, CA). Sorted cells were spun onto microscope slides and stained using a Hema 3 staining kit (Fisher Diagnostics, Middletown, VA) to verify the presence of eosinophils.

\section{Histology and Immunohistochemistry}

Colon tissue samples were rinsed in PBS, fixed in 10\% formalin overnight and embedded for sections. Tissue sections were stained with H\&E for general morphology, toluidine blue to assess mast cell accumulation or processed for immunohistochemistry.

Scoring of disease pathology in H\&E-stained sections was performed as previously described. ${ }^{33}$ Crypt damage was determined by visual assessment and grading based on severity (0 to 4 ), with 0 representing normal baseline morphology, $1=1 / 3$ crypt loss with mild inflammation, $2=2 / 3$ crypt loss with moderate inflammation, $3=$ total crypt loss with intact epithelial layer and severe inflammation, and 4 = total crypt loss with extensive loss of surface epithelium, ulceration, and massive tissue inflammation along the distal colon. In addition, total num- 
A

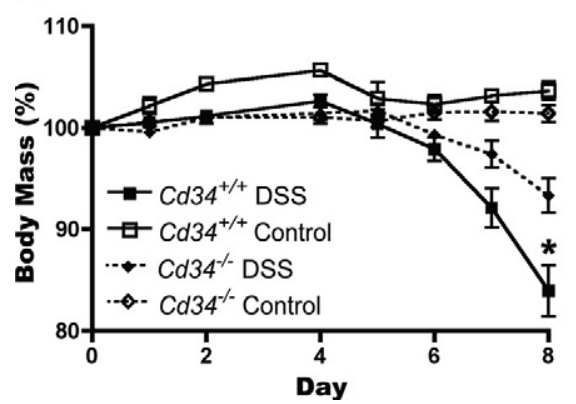

B

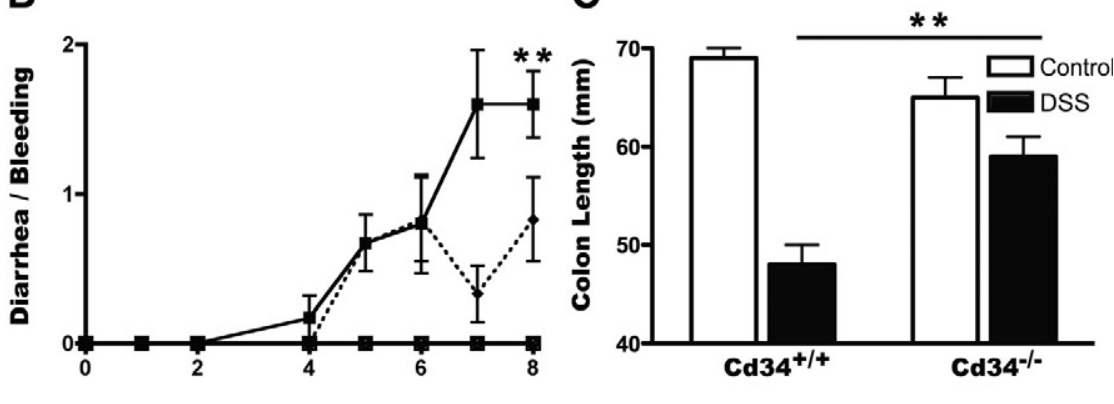

Figure 1. Symptoms of DSS-induced ulcerative colitis are attenuated in Cd34-/- mice. Mice were monitored for 8 days following administration of $3.5 \%$ DSS in drinking water as described in Materials $\&$ Methods. A: Daily body mass measurements, normalized to a starting body mass of $100 \%$. B: Daily disease symptom scores for the presence of diarrhea and/or bleeding $(0-2)$. C: Final colon length measurements following sacrifice on day 8 . Data are representative of five separate experiments. DSS-treated animals $(n=6)$, untreated controls $(n=2) .{ }^{*} P<0.05,{ }^{* * *} P<0.01$; Error bars $=$ SEM.

bers of lymphoid aggregates were quantified along each colon length.

To enumerate tissue eosinophils, colon sections were immunostained with antibodies recognizing mouse MBP purchased from Dr. Jamie Lee (Mayo Clinic, Scottsdale, $A Z$ ). Control slides were stained using a nonspecific rat IgG1 isotype control (Cedarlane Labs Ltd, Burlington, $\mathrm{ON})$. Primary antibodies were then stained using an horseradish peroxidase-conjugated rabbit anti-rat secondary (Dako Canada Inc., Mississauga, ON), developed using diaminobenzidine reagent (Vector Laboratories Inc., Burlingame, CA) and counterstained with $0.1 \%$ methyl green. Eosinophils in three random high power fields $(\times 200)$ were counted from each tissue and averaged.

All slides were analyzed on a Zeiss Axioplan2 microscope (Toronto, ON) and images were captured using a Qimaging Retiga EX CCD camera (Minneapolis, MN) and Openlab 4.0.4 software (PerkinElmer, Waltham, MA).

\section{Cytokine Bead Arrays}

Mouse colon and cecum tissues were dissected and washed in PBS to remove feces. Tissue was homogenized in $500 \mu$ l PBS with protease inhibitor cocktail (Calbiochem, Gibbstown, NJ) using a TissueLyser II (Qiagen, Mississauga, ON). Homogenates were spun down and the supernatant was collected. Cytokine concentrations of macrophage inflammatory protein (MIP)-1 $\alpha$, monocyte chemotactic protein (MCP)-1, IL-6, and TNF- $\alpha$ were measured using the BD Flex CBA kit, according to manufacturer's specifications. Samples were collected on a BD FACSCalibur and analyzed using BD FCAPArray software. Cytokine levels were normalized to total protein content, as determined using a BCA Protein Assay kit (Thermo Scientific, Rockford, IL).

\section{Statistics}

An unpaired student's $t$-test was used for statistical analysis of numbers of lymphoid aggregates, pathology scores, colon length, cytokine assessment, and comparison of individual time points on disease timelines. To compare disease timelines, two-way analysis of variance analysis was performed.

\section{Results \\ Ulcerative Colitis Pathology Is Attenuated in Cd34 ${ }^{-1-}$ Mice}

Following administration of 3.5\% DSS in drinking water, as expected, wild-type animals exhibited a gradual decrease in total body mass over an 8-day timeline (Figure $1 \mathrm{~A})$. Along this timeline, mice also exhibited rectal bleeding and diarrhea from day 4 onwards, with a steady increase in symptom severity (Figure 1B). In $\mathrm{Cd} 34^{-1-}$ animals, some weight loss and diarrhea occurred, although these scores were significantly lower than wildtype controls (Figure 1, A and B). On day 8, mice were sacrificed and colon tissues were processed to assess disease severity. Colon lengths in both wild-type and $\mathrm{Cd} 34^{-1-}$ DSS-induced animals were significantly decreased, compared with untreated animals (Figure 1C), but colon lengths in wild-type animals were significantly shorter than $\mathrm{Cd} 34^{-1-}$ colons, indicating increased disease severity in wild-type animals (Figure 1C).

Histological analysis of colon samples from DSS-induced animals provides further evidence of decreased disease severity in $\mathrm{Cd} 34^{-1-}$ mice. In untreated control animals, no differences were seen in colon morphology between wild-type and $\mathrm{Cd} 34^{-1-}$ mice (Figure 2, C and D). Normal crypt structure and muscle layer thickness, as well as an absence of cellular infiltrate were also the same at baseline. As expected, following DSS treatment, wild-type colon sections exhibited extensive cellular infiltrate, edema, muscle thickening, loss of crypt morphology and surface epithelia structure, lymphoid aggregates (Figure 2B), and extensive ulceration by day 8, particularly in the distal colon (Figure 2, E and G). Multiple ulceration sites were also present along the length of the colon (Figure 2E). In contrast, $\mathrm{Cd} 34^{-1-}$ colon tissues exhibited relatively little crypt loss and surface epithelia remained intact in the distal colon, although low levels of edema, cellular infiltrate, and tissue damage were 
A
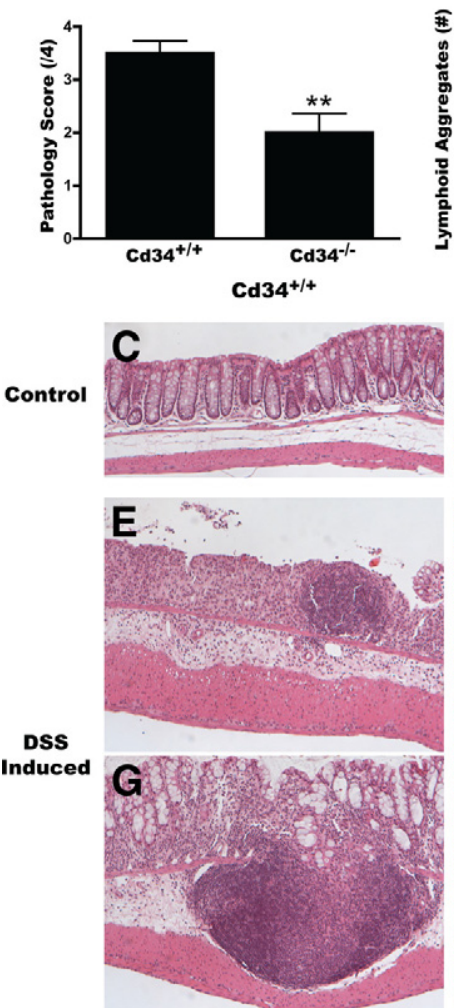

B
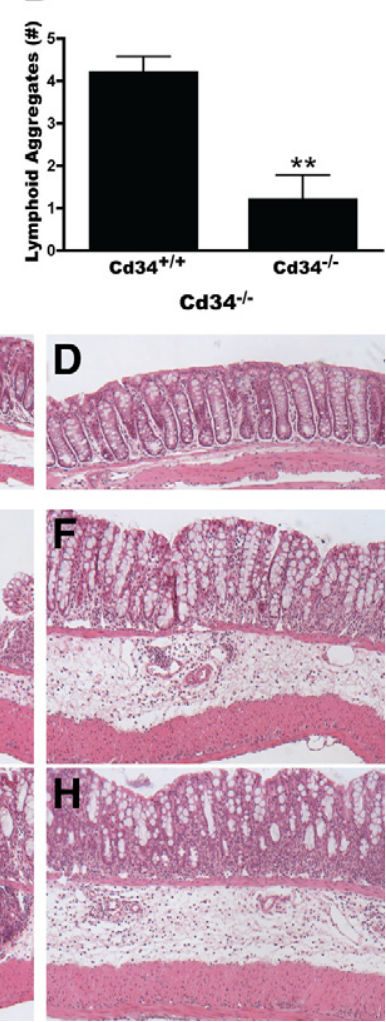

Figure 2. Reduced disease pathology and ulceration in $\mathrm{Cd} 34^{-1-}$ colons. On day 8 , following DSS treatment, colon tissues were fixed overnight in $10 \%$ formalin, paraffin-embedded for longitudinal sections, H\&E-stained, and analyzed by microscopy. A: Clinical pathology scores from $\mathrm{Cd} 34^{+/+}$and $C d 34^{-1-}$ colon sections. $0=$ no sign of disease, $4=$ severe disease as outlined in Materials \& Methods. B: Number of lymphoid aggregates along the length of the distal colon. Representative images of distal colon morphology from control $C d 34^{+/+}(\mathbf{C})$ and $C d 34^{-1-}(\mathbf{D})$ animals and DSS-treated $C d 34^{+/+}(\mathbf{E}, \mathbf{G})$ and $C d 34^{-/-}(\mathbf{F}, \mathbf{H})$ animals, captured at $\times 100$ magnification. $n=5$ for each genotype; ${ }^{*} P<0.05,{ }^{* * *} P<0.01$; Error bars $=$ SEM.

present (Figure 2, F and $\mathrm{H}$ ). Further, very few lymphoid aggregates were present in $\mathrm{Cd} 34^{-1-}$ mice (Figure 2B), and these tended to be smaller in size and restricted to the lamina propria. Clinical scoring of colon pathology confirms a statistically significant reduction in disease pathology scores (Figure 2A), with reduced disease severity in $\mathrm{Cd} 34^{-1-}$ mice following DSS treatment, compared with wild-type controls. These findings suggest that CD34 plays a role in DSS-induced ulcerative colitis, and that loss of CD34 expression protects against severe disease symptoms.

Additionally, assessment of inflammatory cytokine levels in dissociated colon tissues, isolated from DSStreated animals, revealed significant induction of $\mathrm{IL}-6$, MCP-1, TNF $\alpha$, and MIP-1a in wild-type animals. Induction above baseline was also seen in $\mathrm{Cd} 34^{-1-}$ animals, but again, these levels were reduced compared with wildtype animals (Figure 3, A-D). Other cytokines (IL-2, IL-3, IL-4, IL-5, IL-9, IL-10, IL-13, and interferon- $\gamma$ ) were also assayed, but were below detectable levels in all samples, although IL-5 was detectable in IL $5^{\mathrm{Tg}}$ colon tissues at steady state, as expected (data not shown). Taken together, these findings demonstrate that $\mathrm{Cd} 34^{-/-}$mice exhibit a decreased susceptibility to DSS-induced ulcer-

A

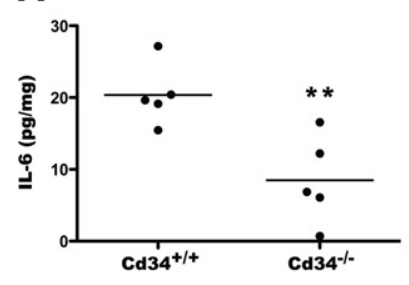

C

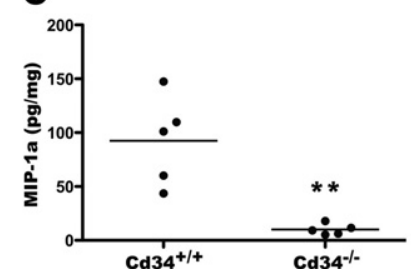

D

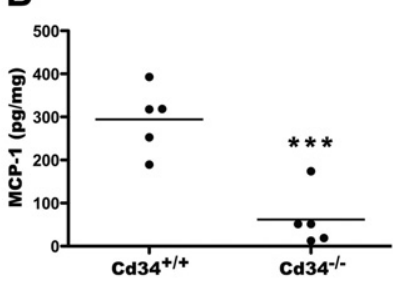

D

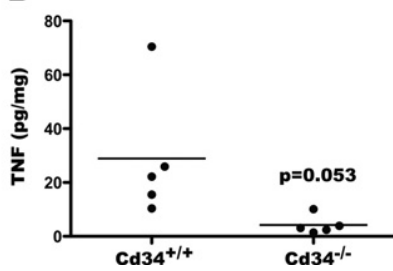

Figure 3. Reduced inflammatory cytokine production in $\mathrm{Cd}_{34^{-1-}}$ colons. On day 8 , following DSS treatment, colon and cecum tissues were isolated and dissociated in PBS. Cytokine concentrations in the collected supernatants were measured by cytometric bead array (CBA). Resulting cytokine values were normalized to total protein content and presented as $\mu$ of cytokine/mg of total protein. Levels of TNF $\alpha(\mathbf{A})$, MCP-1 (B), MIP-1a (C), and IL-6 (D) are shown. Data are representative of two separate experiments. $n=4$ per genotype. ${ }^{*} P<0.05,{ }^{* *} P<0.01,{ }^{* * * * *} P<0.001$; Error bars $=$ SEM.

ative colitis, with decreased disease symptoms, decreased disease pathology, and decreased local inflammatory cytokine production.

\section{CD34 Is Primarily Expressed by Tissue Eosinophils and $\mathrm{Cd} 34^{-1-}$ Mice Exhibit Reduced Eosinophil Infiltration Following DSS Exposure}

To characterize CD34 expression patterns on colon infiltrating cells, we next performed flow cytometric analysis on isolated colon cells from DSS-treated animals. As eosinophils have been shown to play a key role in DSSinduced colitis, and we previously demonstrated a role for CD34 in eosinophil migration, we focused on eosinophils in colon infiltrate. Colon tissue isolates were processed and stained for CD34, CD45, and CCR3 expression and assessed by flow cytometry. Following DSS administration, $\mathrm{CD} 45^{+}$cells represent a large proportion of total colon cells (Figure 4A), whereas CD45 ${ }^{+}$cells were largely absent at baseline. Among the $\mathrm{CD} 45^{+}$cell population, $\sim 30$ to $40 \%$ also expressed CCR3 (Figure $4 \mathrm{~A}$ ) and sorting of $\mathrm{CD}_{4} 5^{+} \mathrm{CCR}^{+}$cells demonstrates that this population consists of eosinophils (Figure 4C). Although few cells were successfully sorted from digested colon tissues, all identifiable cells had eosinophil morphology.

A significant proportion of the total $\mathrm{CD} 45^{+}$cells in DSS-induced colon tissue express CD34 in wild-type mice (Figure 4B, black line). $\mathrm{CD}_{4}{ }^{+}$cells isolated from Cd34 ${ }^{-1-}$ colon do not have detectable CD34-positive staining (Figure 4B, gray-shaded), confirming that the CD34-labeling technique is specific for CD34. The $\mathrm{CD} 4^{+}$staining observed on the CD45 ${ }^{+}$population was further enriched by gating on $\mathrm{CCR}^{+} \mathrm{SSC}^{\text {hi }}$ eosinophils (Figure 4D, black line). Again, Cd34 ${ }^{-1-}$ colon tissues revealed no CD34-positive staining on $\mathrm{CD}_{4} 5^{+} \mathrm{CCR} 3^{+}$ 
A

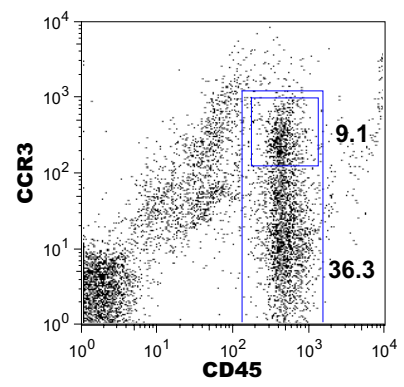

C

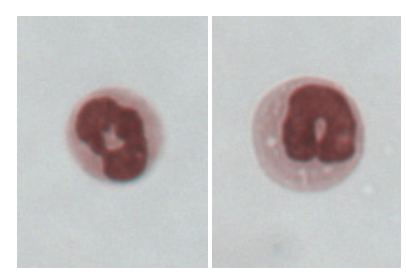

B

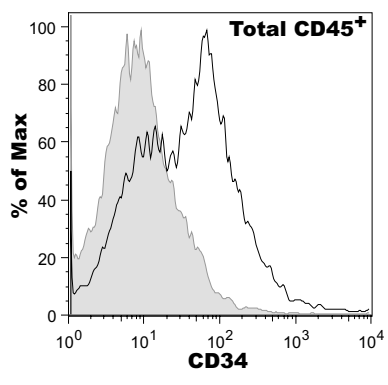

D

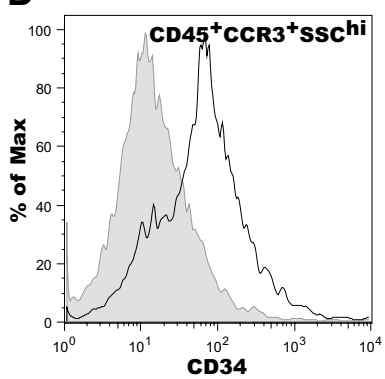

Figure 4. $\mathrm{CD} 34$ is expressed by $\mathrm{CD} 45^{+} \mathrm{CCR} 3^{+} \mathrm{SSC}^{\text {hi }}$ eosinophils in inflamed colon tissue. On day 8 following DSS treatment, colon tissues were excised, collagenase digested and processed for flow cytometry. A: A representative flow cytometry profile of $\mathrm{CD} 45 / \mathrm{CCR} 3$ staining on colon isolates, indicating the gating used to distinguish total $\mathrm{CD} 45^{+}$cells and $\mathrm{CD} 45^{+} / \mathrm{CCR}^{+}$cells (numbers $=\%$ of cells in the $\mathrm{CD} 45^{+} \mathrm{CCR} 3^{+}$or $\mathrm{CD} 45^{+}$gates). Histograms of CD34 expression on total CD $45^{+}$cells $(\mathbf{B})$ and $\mathrm{CD} 45^{+} / \mathrm{CCR}^{+} \mathrm{SSC}^{\text {hi }}$ cells $(\mathbf{D})$. Black lines represent staining on $C d 34^{+/+}$cell isolates, gray-filled histogram represent staining intensity from $\mathrm{Cd} 34^{-/-}$cell isolates. C: Cytospin images of sorted $\mathrm{CD} 45^{+} / \mathrm{CCR}^{+}$cells from colon, demonstrating eosinophil morphology. Plots are representative of three separate experiments.

cells (Figure 4D, gray-shaded). All CD34 ${ }^{+}$cells from isolated colon tissue were $\mathrm{CD}_{4} 5^{+} \mathrm{SSC}^{\text {hi }}$ and $\sim 80 \%$ also fell within a CCR3 ${ }^{\text {hi }}$ gate. The remaining CD34 expression appeared to be on $\mathrm{CCR}^{\mathrm{lo}}$ cells. These findings demonstrate that eosinophils are the primary cell type expressing CD34 in DSS-induced colon tissue of wild-type mice.

Colon tissues were also immunostained using antibodies recognizing the eosinophil-specific protein MBP, to confirm the presence of eosinophils within DSS-treated colon tissues. MBP-staining clearly revealed the presence of tissue-infiltrating eosinophils within both the submucosal and mucosal layers (Figure 5A, brown staining), compared with isotype control-stained tissues (Figure $5 \mathrm{~B})$. At baseline, low levels of eosinophils were present in both wild-type and $\mathrm{Cd} 34^{-1-}$ colon tissues, mainly localized within the intestinal crypts (data not shown). Following DSS treatment, eosinophils were present throughout the submucosal and mucosal layers at greatly increased numbers. Eosinophil numbers were quantified by counting three random high power fields for each sample. Quantification revealed a greater number of infiltrating eosinophils in wild-type animals than in $\mathrm{Cd} 34^{-1-}$ animals, with roughly twice as many eosinophils present in wildtype animals (205.5 \pm 11.7 vs. $120.7 \pm 13.2$ total eosinophils in $\mathrm{Cd} 34^{-1-}$; mean \pm SEM, $n=5$ ) (Figure $5 \mathrm{C}$ ). These findings demonstrate that CD34 expression is induced on eosinophils in DSS colitis, and that loss of CD34 expression results in dramatically decreased eosinophil infiltration of the colon.
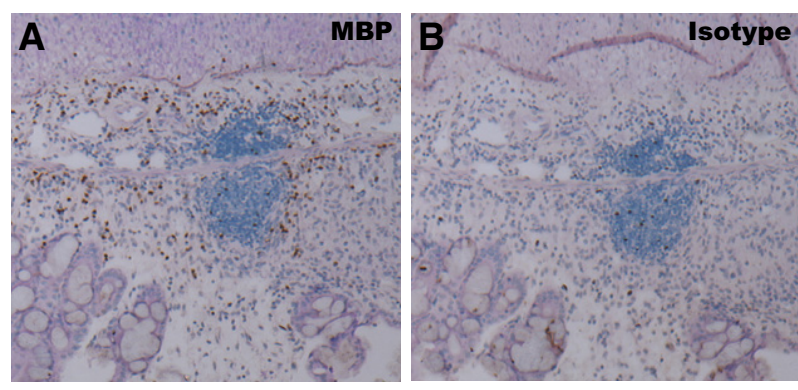

C

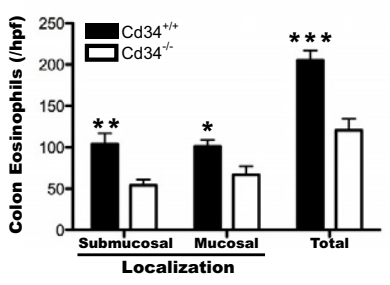

E

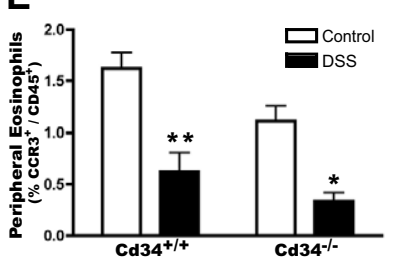

D

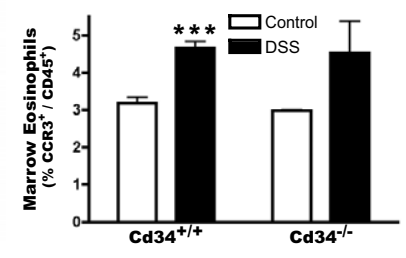

$\mathbf{F}$

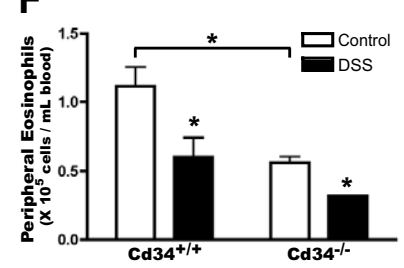

Figure 5. DSS induces colon recruitment of peripheral blood eosinophils, which is attenuated in $C d 34^{-/-}$mice. Formalin-fixed, paraffin-embedded colon tissues were sectioned and prepared for immunohistochemistry by staining with an antibody recognizing MBP or isotype control (rat IgG1), visualized using an horseradish peroxidase-coupled secondary antibody and diaminobenzidine developing reagent and analyzed by microscopy. Representative images of MBP (brown staining) (A) and control isotype staining (B) on DSS-treated colon tissues. C: Average submucosal, mucosal and total eosinophil numbers per high power field (hpf) $(\times 200)$. Three random fields were selected for each sample and averaged. DSS-treated animals were bled through the saphenous vein on day 7 and sacrificed to obtain bone marrow cells, and assessed by flow cytometry for eosinophil numbers (CD $45^{+}$, $\left.\mathrm{CCR}^{+}\right)$. D: Bone marrow eosinophil levels ( $\% \mathrm{CCR}^{+}$of total CD $45^{+}$cells). Peripheral blood eosinophil levels, represented as proportion $\mathrm{CCR}^{+}$of $\mathrm{CD}_{4} 5^{+}$cells $(\mathbf{E})$, or total eosinophil numbers $(\mathbf{F})$ per $\mathrm{ml}$ of blood, calculated based on relative eosinophil numbers ( $\% \mathrm{CCR}^{+}$of total CD $\left.45^{+}\right)$and total white blood cell counts, in $C d 34^{+/+}$and $C d 34^{-/-}$animals. $n=5$ for DSS-treated, 2 to 3 for controls for histology; $n=3$ to 5 for peripheral blood and bone marrow counts. ${ }^{*} P<0.05$, ${ }^{* *} P<0.01$, ${ }^{* * * *} P<0.001$; Error bars $=$ SEM

\section{DSS-Induced Ulcerative Colitis Results in Decreased Circulating Eosinophil Numbers, Despite Increased Bone Marrow Production}

As our data suggests that eosinophils are the key cell type expressing CD34 in the colon during colitis, we also characterized the frequency of eosinophils in the bone marrow and peripheral blood throughout the course of disease. In naïve mice, eosinophils $\left(\mathrm{CCR}^{+} / \mathrm{CD} 45^{+}\right)$represent $\sim 3 \%$ of the total hematopoietic cells (CD45+) in the bone marrow (Figure 5D) and 1 to $2 \%$ of total circulating leukocytes (Figure 5E), in both wild-type and $\mathrm{Cd} 34^{-1-}$ animals. Following DSS induction, the eosinophil numbers increased slightly in the bone marrow to $\sim 4.5 \%$ of the $\mathrm{CD}_{4} 5^{+}$population (Figure 5D). Interestingly, and somewhat unexpectedly, by day 7 following DSS induction, the levels of peripheral blood eosinophils decreased to $<1 \%$ of total leukocytes (Figure $5 \mathrm{E}$ ). When 
normalized to total white blood cell counts, this reveals a decrease in total eosinophil numbers in the periphery (Figure 5F), as eosinophils are recruited into the colon. This is consistent with the recent findings of Vieira et al. ${ }^{16}$ Further, as $\mathrm{Cd} 34^{-1-}$ mice exhibited a slight reduction in both the percentage of eosinophils (Figure $5 \mathrm{E}$ ) and total white blood cell counts at steady state $\left(5.3 \pm 0.8 \times 10^{6}\right.$ cells $/ \mathrm{ml}$ vs. $6.9 \pm 0.5 \times 10^{6} \mathrm{cell} / \mathrm{ml}$ in wild-type; mean \pm SEM, $n=3$ to 5 ), they also exhibited significantly fewer total peripheral blood eosinophils, compared with wildtype mice (Figure 5F). This suggests that at steady state, Cd $34^{-1-}$ have a lower baseline pool of eosinophils, despite similar eosinophil production in the bone marrow.

The reduction in eosinophil numbers following DSS induction was unexpected, as other models of disease associated with eosinophils, such as asthma, are often associated with peripheral blood eosinophilia, as a result of rapid bone marrow precursor expansion. This may reflect the speed of colitis onset in the DSS model, which may be too rapid for a large induction of bone marrow eosinophil precursor expansion. Regardless, this finding demonstrates that peripheral blood eosinophilia is clearly not required for pathology in ulcerative colitis and may provide further insight into the mechanism of colitis induction.

\section{Attenuation of DSS-Induced Ulcerative Colitis Is Due to Loss of CD34 on Bone Marrow Populations, and Not the Microenvironment}

In addition to its expression on hematopoietic precursors, mast cells and eosinophils, CD34 is also expressed on nonhematopoietic cell lineages (such as vascular endothelia). We therefore used bone marrow chimeras to assess the relative importance of hematopoietic versus nonhematopoietic CD34 loss on disease severity. First, wild-type (Ly 5.1) mice were lethally irradiated and reconstituted with either wild-type or $\mathrm{Cd} 34^{-1-}$ bone marrow (Ly 5.2), to assess the role of hematopoietic CD34 expression on disease outcomes. Following DSS administration, both wild-type and $\mathrm{Cd} 34^{-/-}$-reconstituted animals exhibited similar levels of weight loss, potentially reflecting the increased age of reconstituted animals or irradiation-induced damage to the mucosal epithelia (Figure 6A). Significantly, wild-type-reconstituted animals demonstrated an increase in diarrhea/bleeding scores, more severe shortening of the colon and increased colon pathology at the day 8 endpoint, compared with Cd34 ${ }^{-1}$ --reconstituted animals (Figure 6, C, E, and F). These findings suggest that loss of CD34 expression exclusively on bone marrow-derived cells is sufficient to protect from DSS-induced colitis.

In a parallel series of experiments, chimeric animals were generated to assess the relative importance of CD34 expression on nonhematopoietic cells. For these experiments, wild-type or Cd34-1- recipients (Ly 5.2) were irradiated and reconstituted with wild-type (Ly 5.1) bone marrow. Following DSS treatment, no significant difference was seen in weight loss, diarrhea/bleeding scores, colon shortening or pathology between wild-type
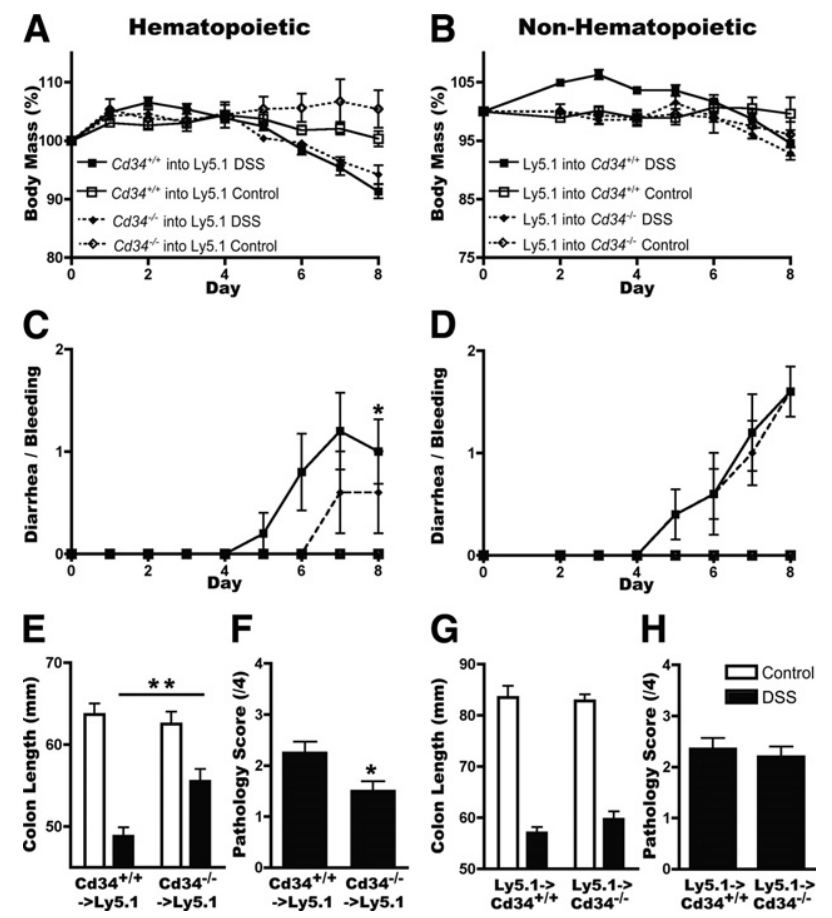

Figure 6. CD 34 expression on hematopoietic, but not nonhematopoietic, cell populations, is critical for disease severity. Chimeric animals were generated by lethal irradiation of recipient animals followed by injection with donor bone marrow cells. Mice were allowed 10 to 12 weeks to recover and assessed for donor reconstitution based on Ly 5.1/5.2 staining in peripheral blood, then administered 3.5\% DSS for 7 days. Daily body mass measurements, normalized to a starting body mass of $100 \%$, daily disease symptom scores, final colon length measurements and tissue pathology scores were measured for all mice. A/C/E/F: Data for Ly 5.1 recipient animals reconstituted with either $C d 34^{+/+}$or $C d 34^{-/-}$bone marrow to assess hematopoietic contributions. B/D/G/H: Data for $C d 34^{+/+}$or $C d 34^{-/-}$recipients reconstituted with Ly 5.1 bone marrow to assess nonhematopoietic contributions. Data are representative of two experiments with each chimera set. DSStreated animals mass, disease scores, and pathology scores $(n=5)$. Colon length $(n=10)$. Untreated controls $n=2$ to $3 ;{ }^{*} P<0.05,{ }^{* * *} P<0.01$; Error bars $=$ SEM

or $\mathrm{Cd} 34^{-1-}$ recipients (Figure $6, \mathrm{~B}, \mathrm{D}, \mathrm{G}$, and $\mathrm{H}$ ). These findings suggest that CD34 expression on hematopoietic cells is most important for the progression of DSSinduced ulcerative colitis, and CD34 expression on nonhematopoietic cells has a minimal role in disease progression.

\section{Hypereosinophilia Results in the Presence of CD34 ${ }^{+}$Eosinophils in the Colon and Colon Shortening, at Steady State, in the Absence of DSS Exposure}

To further investigate the role of eosinophils in colon inflammation and disease we also examined IL $5^{\text {Tg }}$ mice, which exhibit profound eosinophilia, for evidence of intestinal pathology. The IL5 ${ }^{\mathrm{Tg}}$ mice express IL5 under the control of the CD3 $\delta$ promoter, and are hypereosinophilic, with $\sim 60 \%$ eosinophils in the blood, bone marrow, and spleen. ${ }^{31}$ Without DSS treatment, colon length in IL5 ${ }^{\mathrm{T} g}$ animals was significantly reduced, on both the CD34wild-type and $\mathrm{Cd} 34^{-1-}$ backgrounds, compared with non-IL5 ${ }^{\mathrm{Tg}}$ controls (Figure $7 \mathrm{~A}$ ). In the tissues of these 
A

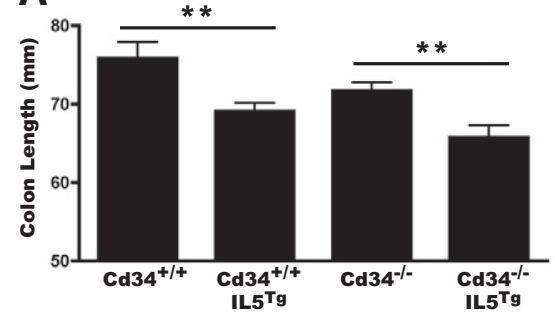

B CD45+ Total

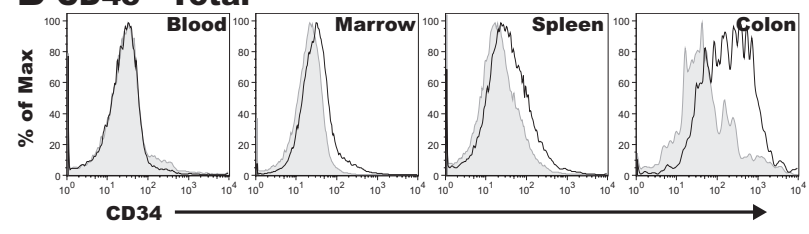

$\mathrm{C} \mathrm{CD45}^{+} / \mathrm{CCR3}^{+} / \mathrm{SSC}^{\mathrm{hi}}$

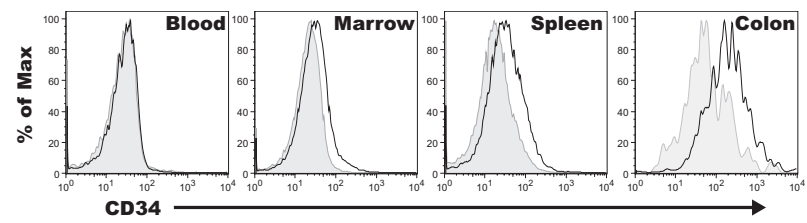

Figure 7. IL5-induced eosinophilia leads to colon shortening, with CD34 expression on colon infiltrating eosinophils. Colon tissues from unchallenged, non-DSS-treated, IL5 $5^{\mathrm{Tg}}$ and $C d 34^{-1-} \mathrm{IL} 5^{\mathrm{Tg}}$ at steady state were excised, measured. and processed for flow cytometry. Blood, bone marrow and spleen tissues were also processed for flow cytometry as described in $\mathrm{Ma}$ terials $\&$ Methods. A: Baseline colon length of $\mathrm{Cd} 34^{+/+}$and $\mathrm{Cd} 34^{-/-}$animals with or without the IL5 transgene. Histogram profiles of CD34 expression on total CD $45^{+}$cells $(\mathbf{B})$ and $\mathrm{CD} 45^{+} / \mathrm{CCR}^{+} \mathrm{SSC}^{\text {hi }}$ cells $(\mathbf{C})$ in peripheral blood, marrow, spleen, and colon isolates. For all histograms, black lines represent staining on cells from $\mathrm{Cd} 34^{+/+} \mathrm{IL} 5^{\mathrm{Tg}}$ tissues and gray-filled histograms represent background staining of cells from $C d 34^{-/-} \mathrm{IL} 5^{\mathrm{Tg}}$ tissues. (Histograms are representative of three separate experiments; $n=9$ to 12 for colon length; ${ }^{* *} P<0.01$; Error bars $=$ SEM).

mice at steady state, CD34 expression was undetectable on $\mathrm{CD} 45^{+}$cells in the peripheral blood and only marginally detectable in the bone marrow and spleen of $\mathrm{Cd} 34^{+/+} \mathrm{IL} 5^{\mathrm{Tg}}$ mice (Figure 7B, black lines), when compared directly to $\mathrm{Cd} 34^{-I-} \mathrm{IL} 5^{\mathrm{Tg}}$ tissues (Figure 7B, gray shaded). This marginal $\mathrm{CD}_{3} 4^{+}$staining was enriched further on $\mathrm{CD} 45^{+} \mathrm{CCR}^{+}{ }^{+} \mathrm{SSC}^{\text {hi }}$ cells, similar to our observations in DSS-treated colon (Figure 7C).

In IL5 ${ }^{\mathrm{Tg}}$ mice, significant CD $45^{+}$inflammatory cell infiltrates were present in the colon at steady state, compared with non-IL $5^{\mathrm{Tg}}$ controls, where very few cells were seen (data not shown). Intriguingly, the highest CD34 expression, in the absence of DSS treatment, was seen on colon infiltrating cells, and was again enriched on $\mathrm{CD}_{4} 5^{+} \mathrm{CCR}^{+} \mathrm{SSC}^{\text {hi }}$ eosinophils isolated from the colon (Figure 7C). These data suggest that eosinophilia alone, in the absence of an external inflammatory stimulus can induce mild colon pathology, with shortening of the colon and immune cell infiltrate, and these features are associated with the influx of $\mathrm{CD} 34^{+}$eosinophils into the colon. Further, these findings suggest that while eosinophilia clearly is not required for the development of ulcerative colitis per se, it may contribute to disease severity and baseline inflammation in the absence of induced colitis.
A

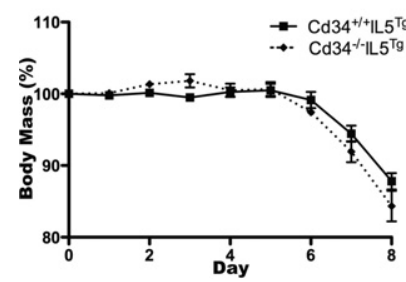

C

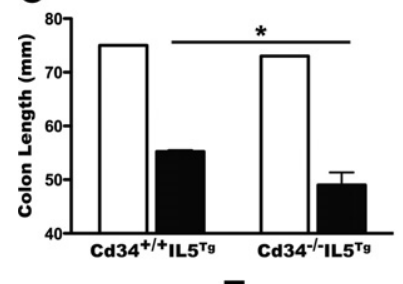

B

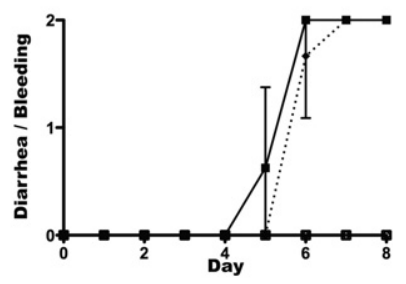

D

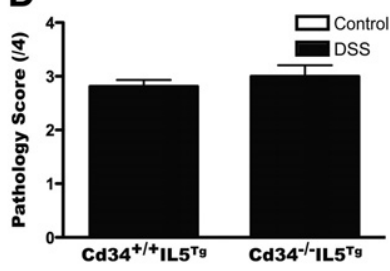

E

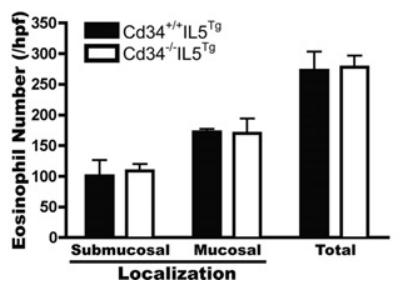

Figure 8. Eosinophilia is sufficient to restore susceptibility to DSS-induced colitis in $\mathrm{Cd} 34^{-1-}$ mice. $\mathrm{Cd} 34^{+/+}$and $\mathrm{Cd} 34^{-/-}$mouse strains were crossed onto the IL $5^{\text {Tg }}$ background to induce eosinophilia. Mice were then treated with 3.5\% DSS for seven days and monitored daily for body mass (A) and diarrhea and bleeding (B). On the day eight endpoint, total colon length was measured $(\mathbf{C})$. Colon tissues were fixed, embedded and stained by H\&E and assessed for clinical pathology (D) as discussed previously and average submucosal, mucosal and total eosinophil numbers (E) were counted per high power field (hpf) (200X). Three random fields were selected for each sample and averaged. $\left(n=4,{ }^{*} P<0.05\right.$, Error bars $=$ SEM $)$.

\section{Eosinophilia Restores DSS-Induced Colitis Susceptibility in Cd34 ${ }^{-1-}$ Mice, on an $1 / 5^{T g}$ Background}

Since our findings in $\mathrm{Cd} 34^{-1-}$ mice suggest that impaired eosinophil migration is sufficient to reduce disease, we also assessed whether we could override this phenotype under conditions of IL-5-induced eosinophilia. $\mathrm{Cd} 34^{+/+} \mathrm{IL} 5^{\mathrm{Tg}}$ and $\mathrm{Cd} 34^{-/-} \mathrm{IL} 5^{\mathrm{Tg}}$ mice were treated with DSS, and assessed for disease induction over 8 days. Contrary to our findings on a non-IL5 ${ }^{\text {Tg }}$ background, on the IL5 $5^{\top 9}$ background, mice exhibited similar weight loss and diarrhea-bleeding symptoms regardless of Cd34 genotype (Figure 8, A and B). In fact, Cd $34^{-1-}$ IL $5^{\text {Tg }}$ animals exhibited slightly more colon shortening at the day 8 time point than $\mathrm{Cd} 34^{+/+} \mathrm{IL} 5^{\mathrm{Tg}}$ controls (Figure $8 \mathrm{C}$ ) and histological assessment revealed no difference in clinical score (Figure 8D). Quantification of colon eosinophil accumulation following DSS exposure revealed a greatly increased number of eosinophils in IL $5^{\mathrm{Tg}}$ mice (Figure 8E), in excess of numbers seen in wild-type non-IL5 ${ }^{\mathrm{Tg}}$ animals (Figure $5 \mathrm{C}$ ). Further, eosinophil numbers were equally elevated in $\mathrm{Cd} 34^{-1-} \mathrm{IL} 5^{\mathrm{Tg}}$ animals, following DSS exposure (Figure $8 \mathrm{E}$ ). These findings demonstrate that hypereosinophilia, induced by increased IL-5 production, is sufficient to overcome the 
decreased eosinophil migration and decreased susceptibility to colitis observed in $\mathrm{Cd} 34^{-/-}$animals and provide further support for the hypothesis that colon-infiltrating eosinophils are important mediators of pathogenesis.

\section{Discussion}

Mice treated with DSS develop an acute experimental ulcerative colitis that closely resembles human colitis and serves as a valuable model of disease. Since there is evidence suggesting an essential role for eosinophils in ulcerative colitis and data showing that CD34 is required for efficient eosinophil trafficking, we investigated the effect of CD34 loss on disease outcomes. Following DSS treatment, we found a significant attenuation of disease symptoms in $\mathrm{Cd} 34^{-1-}$ mice. Cd $34^{-1-}$ mice exhibit less severe weight loss, reduced colon shortening, and lower overall diarrhea/rectal bleeding. In addition, histological analysis reveals decreased eosinophil infiltration, decreased clinical pathology, reduced ulceration, reduced numbers of lymphoid aggregates, and reduced inflammatory cytokine production in $\mathrm{Cd} 34^{-1-}$ colon tissues. Furthermore, we found that eosinophils entering the colon express high levels of CD34 and are the predominant CD34-expressing hematopoietic cell type in the colon following disease onset.

Our previous findings have demonstrated key roles for CD34 in optimal cell migration of hematopoietic cells, particularly mast cells and eosinophils. On mast cells, CD34 expression prevented cell-cell aggregation in vitro. ${ }^{28}$ In an asthma model, Cd $34^{-1-}$ mice exhibit decreased disease pathology due to CD34 loss on hematopoietic cells, accompanied by a reduction in both mast cell and eosinophil recruitment to the lung. In addition, Cd $34^{-1-}$ eosinophils exhibit impaired migration in an in vitro assay, ${ }^{27}$ suggesting that loss of CD34 expression, alone, is sufficient to impair eosinophil infiltration. In this study, we propose a similar role for CD34 on eosinophils in the DSS-induction model of ulcerative colitis, whereby CD34 expression is required for efficient eosinophil infiltration of the colon, which, in turn, leads to tissue damage and pathology.

Our findings demonstrate that CD34 is prominently expressed on $\mathrm{CD}_{4} 5^{+} \mathrm{CCR} 3^{+} \mathrm{SSC}^{\text {hi }}$ eosinophils within coIon tissue following DSS-treatment. The presence of eosinophils within inflamed colon tissues was confirmed by MBP-staining of colon sections. Low levels of eosinophils were present at baseline, with a dramatic increase in tissue eosinophils at the day 8-endpoint. Analogous to our findings in the asthma model, Cd $34^{-I-}$ mice exhibited drastically reduced numbers of eosinophils within the colon, compared with wild-type controls. CD34 is also expressed by mast cells, although toluidine blue staining revealed very low levels of mast cells present in tissues both before and after DSS-treatment ( $\sim 1$ to 2 cells/section; data not shown). Thus, it is unlikely that CD34 expression on mast cells accounts for the differences in disease pathology seen in $\mathrm{Cd} 34^{-1-}$ mice. These findings support the hypothesis that CD34 is required for optimal infiltration of eosinophils into the colon following DSS- treatment, and that eosinophil infiltration, in turn, is required for the development of severe colitis pathology.

Assessment of cytokine levels in colon tissue isolates also revealed reduced inflammation in $\mathrm{Cd} 34^{-1-}$ mice. Following DSS-induction, levels of the pro-inflammatory cytokines TNF $\alpha$ and IL-6 were increased in wild-type mice, as previously published, ${ }^{34,35}$ and found at lower levels in $\mathrm{Cd} 34^{-1-}$ animals. TNF $\alpha$ and IL-6 are released by resident macrophages, following DSS-induced increases in mucosal permeability ${ }^{36}$ on exposure to commensal gut flora. In fact, blocking TNF $\alpha$, using anti-TNF $\alpha$ antibodies in vivo, results in decreased disease pathology in the chronic DSS colitis mouse model, ${ }^{37}$ and has had success in patients with Crohn's disease. ${ }^{38}$ Interestingly, we also detected high levels of the chemokines MIP-1a and MCP-1 in the colon of wild-type, compared with Cd34 $4^{-1-}$ mice, although these chemokines do not appear to be released into the serum during acute DSS-induced colitis. ${ }^{34}$ Interestingly, MIP-1a administration is sufficient to exacerbate inflammatory bowel disease in a trinitrobenzene sulfonic acid-induced disease model. ${ }^{39}$ It remains unclear, in our model, whether any of these cytokines are the cause of the reduced eosinophil accumulation and disease severity observed in $\mathrm{Cd} 34^{-1-}$ mice, or merely an effect. Our previous findings demonstrated a cell-intrinsic defect in $\mathrm{Cd} 34^{-1-}$ eosinophil migration in vitro, ${ }^{27}$ but the reduced local cytokine levels in Cd34 ${ }^{-1-}$ mice may exacerbate this defect. Alternatively, the reduced levels of inflammatory cytokines in colon tissues of $\mathrm{Cd} 34^{-/-}$mice may be a direct result of impaired eosinophil accumulation, resulting in reduced local tissue damage and inflammation.

To further clarify the role CD34 plays in ulcerative colitis, we used bone marrow chimeras to determine the relative importance of $\mathrm{CD} 34$ on hematopoietic versus nonhematopoietic tissues. These findings reveal a critical role for CD34 on hematopoietic cells, as wild-type (Ly 5.1) recipient animals reconstituted with $\mathrm{Cd} 34^{-\prime-}$ bone marrow exhibited attenuated disease severity similar to that seen in Cd34-null animals. These findings suggest that CD34 expression on nonhematopoietic lineages (ie, endothelial cells) has a minimal effect on disease pathology and further supports the conclusion that CD34 expression on eosinophils is critical for disease progression.

By crossing $\mathrm{Cd} 34^{-1-}$ animals onto the IL $5^{\mathrm{Tg}}$ background, to induce hypereosinophilia, we were able to restore susceptibility to DSS-induced colitis. Following DSS treatment, Cd $34^{-1-} \mathrm{IL} 5^{\text {Tg }}$ mice had similar symptoms and pathology and slightly increased colon shortening, when compared with $\mathrm{Cd} 34^{+/+} \mathrm{IL} 5^{\mathrm{Tg}}$ control animals. Further, tissue eosinophil counts in IL $5^{\mathrm{Tg}}$ animals ( $\sim 300$ cells/hpf) exceeded eosinophil numbers in wildtype mice after DSS treatment ( 200 cell/hpf), regardless of CD34 expression. Thus, chronic eosinophilia alone is sufficient to overcome the migration defect of $\mathrm{Cd} 34^{-1-}$ eosinophils and restore disease susceptibility in $\mathrm{Cd} 34^{-1-}$ mice.

Intriguingly, following DSS-treatment, we observed decreased eosinophil numbers in the peripheral blood of wild-type mice, despite a slight increase in bone marrow 
production, likely due to recruitment of eosinophils from the periphery to the inflamed tissue, which is in agreement with recent findings. ${ }^{16}$ This finding is quite different from observations in models such as asthma, and was somewhat surprising. In models of allergic disease, eosinophil numbers commonly increase and disease pathology is associated with peripheral blood eosinophilia. An absence of peripheral blood eosinophil expansion in DSS-induced colitis may reflect the acute nature of disease in this model. In DSS-induced colitis, the inflammatory insult leads to a rapid recruitment of eosinophils into the colon. In contrast ovalbumin-induced asthma requires $\sim 1$ month of priming and challenges to induce disease. Extended time courses may provide sufficient time for the expansion of bone marrow eosinophils and subsequent peripheral blood eosinophilia. This same phenomenon may also explain the observation that IL5 $5^{-1-}$ mice exhibit normal disease pathology in the DSSinduced colitis model. ${ }^{13,18}$ IL5 is a critical regulator of eosinophil expansion and survival, and as such, normal colitis susceptibility in IL $5^{-1-}$ mice has cast doubt on the role of eosinophil in pathology of this disease. However, IL5 $5^{-1-}$ mice do produce eosinophils, despite exhibiting reduced eosinophil expansion and proliferation. Our findings suggest that eosinophil expansion, which is important in allergy, is dispensable for normal disease progression in colitis and instead, factors regulating eosinophil recruitment such as eotaxin-1/2, ${ }^{12,13}$ intercellular adhesion molecule- $1^{14}$ or CD34 are more important. This is a very important observation when considering the development of novel therapies for the treatment of ulcerative colitis and suggests that targeting eosinophil recruitment, rather than eosinophil expansion, will be more therapeutic.

IL-5 $5^{\text {Tg }}$ mice exhibit significant chronic eosinophilia with $>60 \%$ eosinophils (as a proportion of total white blood cells) in peripheral blood, bone marrow and spleen. We observed a small, but significant decrease, in colon length at steady state in both $1 \mathrm{~L} 5^{\mathrm{Tg}}$ and $\mathrm{Cd} 34^{-1-} \mathrm{IL} 5^{\mathrm{Tg}}$ animals, compared with controls. In addition, before disease induction, IL5 ${ }^{\mathrm{Tg}}$ colon tissues exhibited significant inflammatory cell infiltrates, including $\mathrm{CCR}^{+}{ }^{+} \mathrm{SSC}^{\text {hi }}$ eosinophils. Initial reports on $\mathrm{IL} 5^{\mathrm{Tg}}$ mice revealed that $\sim 70 \%$ of these mice spontaneously die by 12 months of age. ${ }^{31}$ Interestingly, surviving animals display severe inflammatory pathologies including skin lesions and lower bowel inflammation. ${ }^{31}$ Our findings suggest that even at younger ages (6 to 12 weeks) IL5 $5^{\text {Tg }}$ mice have chronic, low-level gut inflammation, with eosinophil infiltration. Further, in the absence of DSS treatment, CD34 expression is present on eosinophils at low levels in the bone marrow and spleen, and more significantly, is increased on colon-infiltrating eosinophils. These findings demonstrate that chronic exposure to IL5 and eosinophilia are sufficient to induce low-level colon inflammation, which may progress to more severe disease and explain the pathology in aged IL $5^{\mathrm{Tg}}$ animals.

Eosinophils are implicated in a variety of inflammatory diseases and our data demonstrate that the loss of CD34 results in attenuation of ulcerative colitis, with decreased pathology, likely due to impaired eosinophil recruitment.
As $\mathrm{Cd} 34^{-1-}$ mice exhibit no major defects in development or in maintaining homeostasis, these findings suggest that the CD34 molecule, itself, may be a valuable therapeutic target for the treatment of inflammatory diseases, including ulcerative colitis, by inhibiting immune cell infiltration into the tissue.

\section{Acknowledgments}

We are grateful to Dr. Jamie Lee (Mayo Clinic, Scottsdale, Arizona) for providing pCD3-IL5 ${ }^{\mathrm{Tg}}$ mice and the anti-MBP antibody; Bruce Vallance for technical expertise and advice Takahide Murakami (The BRC genotyping service) for mouse genotyping and Matt Cowan and Les Rollins (BRC Animal Care Facility).

\section{References}

1. Hendrickson BA, Gokhale R, Cho JH: Clinical aspects and pathophysiology of inflammatory bowel disease. Clin Microbiol Rev 2002, 15:79-94

2. Torres MI, Rios A: Current view of the immunopathogenesis in inflammatory bowel disease and its implications for therapy. World J Gastroenterol 2008, 14:1972-1980

3. Bischoff SC, Wedemeyer J, Herrmann A, Meier PN, Trautwein C Cetin Y, Maschek H, Stolte M, Gebel M, Manns MP: Quantitative assessment of intestinal eosinophils and mast cells in inflammatory bowel disease. Histopathology 1996, 28:1-13

4. Carvalho AT, Elia CC, de Souza HS, Elias PR, Pontes EL, Lukashok HP, de Freitas FC, Lapa e Silva JR: Immunohistochemical study of intestinal eosinophils in inflammatory bowel disease. J Clin Gastroenterol 2003, 36:120-125

5. Makiyama K, Kanzaki S, Yamasaki K, Zea-Iriarte W, Tsuji Y: Activation of eosinophils in the pathophysiology of ulcerative colitis. J Gastroenterol 1995, 30 Suppl 8:64-69

6. Chen W, Paulus B, Shu D, Wilson, Chadwick V: Increased serum levels of eotaxin in patients with inflammatory bowel disease. Scand J Gastroenterol 2001, 36:515-520

7. Lampinen M, Carlson M, Sangfelt P, Taha Y, Thorn M, Loof L, Raab Y Venge P: IL-5 and TNF-alpha participate in recruitment of eosinophils to intestinal mucosa in ulcerative colitis. Dig Dis Sci 2001, 46:2004-2009

8. Carlson M, Raab Y, Peterson C, Hallgren R, Venge P: Increased intraluminal release of eosinophil granule proteins EPO. ECP, EPX, and cytokines in ulcerative colitis and proctitis in segmental perfusion. Am J Gastroenterol 1999, 94:1876-1883

9. Sangfelt P, Carlson M, Thorn M, Loof L, Raab Y: Neutrophil and eosinophil granule proteins as markers of response to local prednisolone treatment in distal ulcerative colitis and proctitis. Am J Gastroenterol 2001, 96:1085-1090

10. Bischoff SC, Mayer J, Nguyen QT, Stolte M, Manns MP: Immunohistological assessment of intestinal eosinophil activation in patients with eosinophilic gastroenteritis and inflammatory bowel disease. Am J Gastroenterol 1999, 94:3521-3529

11. Powell N, Walker MM, Talley NJ: Gastrointestinal eosinophils in health, disease and functional disorders. Nat Rev Gastroenterol Hepatol 2010, 7:146-156

12. Ahrens R, Waddell A, Seidu L, Blanchard C, Carey R, Forbes E, Lampinen M, Wilson T, Cohen E, Stringer K, Ballard E, Munitz A, Xu $\mathrm{H}$, Lee N, Lee JJ, Rothenberg ME, Denson L, Hogan SP: Intestinal macrophage/epithelial cell-derived CCL11/eotaxin-1 mediates eosinophil recruitment and function in pediatric ulcerative colitis. J Immunol 2008, 181:7390-7399

13. Forbes E, Murase T, Yang M, Matthaei KI, Lee JJ, Lee NA, Foster PS, Hogan SP: Immunopathogenesis of experimental ulcerative colitis is mediated by eosinophil peroxidase. J Immunol 2004, 172:5664-5675

14. Forbes E, Hulett M, Ahrens R, Wagner N, Smart V, Matthaei KI, Brandt EB, Dent LA, Rothenberg ME, Tang M, Foster PS, Hogan SP: ICAM- 
1-dependent pathways regulate colonic eosinophilic inflammation. J Leukoc Biol 2006, 80:330-341

15. Shichijo K, Makiyama K, Wen CY, Matsuu M, Nakayama T, Nakashima M, Ihara M, Sekine I: Antibody to eosinophil cationic protein suppresses dextran sulfate sodium-induced colitis in rats. World J Gastroenterol 2005, 11:4505-4510

16. Vieira AT, Fagundes CT, Alessandri AL, Castor MG, Guabiraba R, Borges VO, Silveira KD, Vieira EL, Goncalves JL, Silva TA, Deruaz M, Proudfoot AE, Sousa LP, Teixeira MM: Treatment with a novel chemokine-binding protein or eosinophil lineage-ablation protects mice from experimental colitis. Am J Pathol 2009, 175:2382-2391

17. Kopf M, Brombacher F, Hodgkin PD, Ramsay AJ, Milbourne EA, Dai WJ, Ovington KS, Behm CA, Kohler G, Young IG, Matthaei KI: IL-5deficient mice have a developmental defect in CD5+ B-1 cells and lack eosinophilia but have normal antibody and cytotoxic $T$ cell responses. Immunity 1996, 4:15-24

18. Stevceva L, Pavli P, Husband A, Matthaei KI, Young IG, Doe WF: Eosinophilia is attenuated in experimental colitis induced in IL-5 deficient mice. Genes Immun 2000, 1:213-218

19. Beauchamp JR, Heslop L, Yu DS, Tajbakhsh S, Kelly RG, Wernig A, Buckingham ME, Partridge TA, Zammit PS: Expression of CD34 and Myf5 defines the majority of quiescent adult skeletal muscle satellite cells. J Cell Biol 2000, 151:1221-1234

20. Joe AW, Yi L, Natarajan A, Le Grand F, So L, Wang J, Rudnicki MA, Rossi FM: Muscle injury activates resident fibro/adipogenic progenitors that facilitate myogenesis. Nat Cell Biol 2010, 12:153-163

21. Trempus CS, Morris RJ, Bortner CD, Cotsarelis G, Faircloth RS, Reece JM, Tennant RW: Enrichment for living murine keratinocytes from the hair follicle bulge with the cell surface marker CD34. J Invest Dermatol 2003, 120:501-511

22. Baumheter S, Singer MS, Henzel W, Hemmerich S, Renz M, Rosen $\mathrm{SD}$, Lasky LA: Binding of L-selectin to the vascular sialomucin CD34. Science 1993, 262:436-438

23. Baumhueter S, Dybdal N, Kyle C, Lasky LA: Global vascular expression of murine CD34, a sialomucin-like endothelial ligand for L-selectin. Blood 1994, 84:2554-2565

24. Nielsen JS, McNagny KM: Novel functions of the CD34 family. J Cell Sci 2008, 121:3683-3692

25. Drew E, Merkens H, Chelliah S, Doyonnas R, McNagny KM: CD34 is a specific marker of mature murine mast cells. Exp Hematol 2002, 30:1211-1218

26. Radinger M, Johansson AK, Sitkauskiene B, Sjostrand M, Lotvall J: Eotaxin-2 regulates newly produced and $\mathrm{CD} 34$ airway eosinophils after allergen exposure. J Allergy Clin Immunol 2004, 113:1109-1116

27. Blanchet MR, Maltby S, Haddon DJ, Merkens H, Zbytnuik L, McNagny KM: CD34 facilitates the development of allergic asthma. Blood 2007, 110:2005-2012
28. Drew E, Merzaban JS, Seo W, Ziltener HJ, McNagny KM: CD34 and CD43 inhibit mast cell adhesion and are required for optimal mast cell reconstitution. Immunity 2005, 22:43-57

29. Nielsen JS, McNagny KM: Influence of host irradiation on long-term engraftment by CD34-deficient hematopoietic stem cells. Blood 2007, 110:1076-1077

30. Suzuki A, Andrew DP, Gonzalo JA, Fukumoto M, Spellberg J, Hashiyama M, Takimoto H, Gerwin N, Webb I, Molineux G, Amakawa R, Tada Y, Wakeham A, Brown J, McNiece I, Ley K, Butcher EC, Suda T, GutierrezRamos JC, Mak TW: CD34-deficient mice have reduced eosinophil accumulation after allergen exposure and show a novel crossreactive 90-kD protein. Blood 1996, 87:3550-3562

31. Lee NA, McGarry MP, Larson KA, Horton MA, Kristensen AB, Lee JJ: Expression of IL-5 in thymocytes/T cells leads to the development of a massive eosinophilia, extramedullary eosinophilopoiesis, and unique histopathologies. J Immunol 1997, 158:1332-1344

32. Okayasu I, Hatakeyama S, Yamada M, Ohkusa T, Inagaki Y, Nakaya R: A novel method in the induction of reliable experimental acute and chronic ulcerative colitis in mice. Gastroenterology 1990, 98:694-702

33. Cooper HS, Murthy SN, Shah RS, Sedergran DJ: Clinicopathologic study of dextran sulfate sodium experimental murine colitis. Lab Invest 1993, 69:238-249

34. Alex P, Zachos NC, Nguyen T, Gonzales L, Chen TE, Conklin LS Centola M, Li X: Distinct cytokine patterns identified from multiplex profiles of murine DSS and TNBS-induced colitis. Inflamm Bowel Dis 2009, 15:341-352

35. Dieleman LA, Ridwan BU, Tennyson GS, Beagley KW, Bucy RP Elson CO: Dextran sulfate sodium-induced colitis occurs in severe combined immunodeficient mice. Gastroenterology 1994, 107:16431652

36. Kitajima S, Takuma S, Morimoto M: Changes in colonic mucosal permeability in mouse colitis induced with dextran sulfate sodium. Exp Anim 1999, 48:137-143

37. Kojouharoff G, Hans W, Obermeier F, Mannel DN, Andus T, Scholmerich J, Gross V, Falk W: Neutralization of tumour necrosis factor (TNF) but not of IL-1 reduces inflammation in chronic dextran sulphate sodium-induced colitis in mice. Clin Exp Immunol 1997, 107:353-358

38. van Dullemen HM, van Deventer SJ, Hommes DW, Bijl HA, Jansen J, Tytgat GN, Woody J: Treatment of Crohn's disease with anti-tumor necrosis factor chimeric monoclonal antibody (cA2). Gastroenterology 1995, 109:129-135

39. Pender SL, Chance V, Whiting CV, Buckley M, Edwards M, Pettipher $\mathrm{R}$, MacDonald TT: Systemic administration of the chemokine macrophage inflammatory protein 1alpha exacerbates inflammatory bowel disease in a mouse model. Gut 2005, 54:1114-1120 